\title{
Arthroscopic Treatment of Posterior Ankle Impingement Syndrome: Mid-Term Clinical Results and a Learning Curve
}

\author{
Kazuya Sugimoto, MD., Ph.D., Shinji Isomoto, M.D., Ph.D., Norihiro Samoto, M.D., Ph.D., \\ Tomohiro Matsui, M.D., Ph.D., and Yasuhito Tanaka, M.D., Ph.D.
}

\begin{abstract}
Purpose: To report mid-term clinical results of posterior ankle arthroscopy in the treatment of posterior ankle impingement syndrome (PAIS) and to assess the learning curve and its influence on the results. Methods: This was a retrospective evaluation of the clinical outcomes of posterior ankle arthroscopy and its learning curve in a series of patients with PAIS. Demographic and clinical data, surgical time, the American Orthopaedic Foot Ankle Society (AOFAS) ankle/ hindfoot scores, and time to resumption of sports were recorded. Results: Fifty-nine patients with 72 posterior ankle arthroscopies were evaluated at a mean follow-up period of 60 months (24-133 months). Causes of PAIS were an os trigonum (50), a large posterior talar process (14), and soft-tissue impingement (8). There were 29 male and 30 female patients. The average age was 21.8 years (12-74 years). The average preoperative AOFAS score improved significantly from 79.6 to 97.6 postoperatively $(P<.0001)$. The average time taken to resume training was 5.3 weeks, and the time to return to a competitive condition was 13.4 weeks. The times to resumption of training were shorter in elite athletes than local competitive athletes. The learning curve of the posterior ankle arthroscopy was detected and determined by a logarithmic trendline and moving averages. An experience of 26 cases was required to be proficient in posterior arthroscopies. The postoperative AOFAS scores were not statistically different between the initial and the latest 10 series each. Conclusions: The mid-term follow-up results of endoscopic treatment for the PAIS were good, with a high success rate in returning to sports activities. Although a learning curve effect was detected in our series of arthroscopic treatment for the PAIS due to os trigonum, a low volume of experience did not affect the results. Level of Evidence: Level IV, therapeutic case series.
\end{abstract}

$\mathbf{E}^{1}$ lite athletes, such as football players and dancers, are the most common patients to develop posterior ankle impingement syndrome (PAIS). ${ }^{1-4}$ Bony impingement by an os trigonum or by a large posterior talar process is the major cause of the syndrome. ${ }^{5-8} \mathrm{In}$

From the Nara Prefecture General Medical Center (K.S., S.I.); Kokuho Chuo Hospital (N.S.); Imperial Gift Saiseikai Nara Hospital (T.M.); and Nara Medical University, School of Medicine (Y.T.), Nara, Japan.

The authors report that they have no conflicts of interest in the authorship and publication of this article. Full ICMJE author disclosure forms are available for this article online, as supplementary material.

This study was performed at the Nara Prefecture General Medical Center and the Imperial Gift Saiseikai Nara Hospital.

Received September 12, 2020; accepted March 30, 2021.

Address correspondence to Dr. Kazuya Sugimoto, 897-5, 2-chome, Shichijonishimachi, Nara-shi, Japan, 6308581.E-mail:kzort@kcn.jp

(C) 2021 THE AUTHORS. Published by Elsevier Inc. on behalf of the Arthroscopy Association of North America. This is an open access article under the CC BY-NC-ND license (http://creativecommons.org/licenses/by-nc-nd/4.0/). 2666-061X/201543

https://doi.org/10.1016/j.asmr.2021.03.013 1990s, several reports were published on arthroscopic excision of an os trigonum from anterior or lateral portals; however, theses arthroscopic techniques have not been used widely. ${ }^{9-12}$ Conventional open surgery after failed conservative treatments was commonly performed for bony impingements, until in 2000, van Dijk et al. ${ }^{13}$ reported an arthroscopic approach for the PAIS using 2 posterior portals.

Arthroscopy of the posterior ankle and hindfoot enables direct, detailed examination of the area, including an os trigonum or posterior talar process, the posterior half of the ankle joint, the posterior facet of the subtalar joint, the intermalleolar ligament, the posterior talofibular ligament, and the flexor hallucis longus tendon and its sheath. ${ }^{14,15}$

With the widespread use of posterior ankle arthroscopy, the understanding of the local anatomy and pathology of the posterior ankle has deepened along with establishment of soft-tissue impingement without any bone abnormalities. Thus, posterior ankle arthroscopy is now an indispensable tool for the diagnosis and treatment of posterior ankle symptoms, including the PAIS. ${ }^{16}$ 
Arthroscopic treatment of the PAIS is safer and less invasive, with lower rates of complications than the conventional open procedure. ${ }^{17-21}$ It is essential to understand the local anatomy of the posterior ankle to avoid any injuries to the normal structures of the joint, tendons, vessels, and nerves. ${ }^{22-25}$

Although there have been several reports on the arthroscopic treatment of the PAIS with a short-term follow up, ${ }^{1-3,6,16,17,19,20,26,27}$ very few reports exist on mid-term results of arthroscopic treatment for the PAIS and their relationship with the skill of posterior arthroscopy.

There are various indicators to measure the skills required for a specific surgical procedure. Time-based metrics are commonly used to assess the learning curve. ${ }^{28}$ We used surgical time as an indicator of the operative skill in the arthroscopic treatment of the PAIS. ${ }^{29}$

The purposes of this study were to report mid-term clinical results of posterior ankle arthroscopy in the treatment of the PAIS and to assess the learning curve and its influence on the results. We hypothesized that the American Orthopaedic Foot Ankle Society (AOFAS) ankle/hindfoot scores would improve after ankle arthroscopy for PAIS and that we will observe evidence of a learning curve.

\section{Methods}

This study was performed in accordance with the ethical standard in the 1964 Declaration of Helsinki. Details that might disclose the identity of the subjects under study have been omitted. This study was approved by the institutional review board of the Nara Prefecture General Medical Center (ID: 370).

\section{Patient Selection}

This is a retrospective case series of patients who underwent arthroscopic treatment for the PAIS between December 2008 and June 2018. Patients who underwent posterior ankle arthroscopy at the Imperial Gift Saiseikai Nara Hospital or at the Nara Prefecture General Medical Center were identified. The inclusion criteria were typical patients who complained of symptoms compatible to PAIS caused by an os trigonum or a large posterior talar process. Patients with the symptomatic ankles without an ossicle or a posterior talar process also were included if a soft-tissue impingement was suggested by magnetic resonance imaging (MRI). Local synovitis, immature scarring of ligament fibers, and/or subchondral bone edema at the posterior end of the tibial plafond were shown on MRI in the ankles with softtissue impingement. The exclusion criteria were patients whose ossicle in the ankle was not an os trigonum, but a loose body or a bipartite talus examined by arthroscopy. Patients followed less than 24 months after the operation also were excluded. All patients complained of posterior ankle pain during activities. Posterior ankle pain is typically induced by forced plantar flexion of the affected ankle. After failed conservative treatments including rest, medication, and/or taping for at least 3 months, the patients underwent posterior ankle arthroscopy.

All ankles were operated by 2 operators (K.S., S.I.) who were approved by the Japanese Orthopaedic Association and by the Japan Sport Association. One of the 2 operators had performed more than a thousand knee arthroscopies and about 200 anterior ankle arthroscopies, whereas the other operator had performed about a hundred knee and 30 anterior ankle arthroscopies. Both were new to posterior ankle arthroscopy. Sports-related patients were classified into 3 groups: S1 were professional and/or national championship participants, S2 were local competitive athletes, and S3 were patients who enjoyed recreational sports activities

\section{Operative Technique}

Arthroscopic treatments were performed placing the patient in the prone position and the symptomatic ankle was elevated $10 \mathrm{~cm}$ with a small triangular support under the leg. The posterior approach with 2 portals as described by van Dijk et al. ${ }^{13}$ was used. A 2.7$\mathrm{mm}$ diameter $30^{\circ}$ oblique scope was inserted from the lateral portal and another instrument from the medial portal. An irrigation pump was used with an initial setting of $60 \mathrm{~mm} \mathrm{Hg}$ pressure and $0.5 \mathrm{~mL} / \mathrm{s}$ flow volume, and adjusted according to the bleeding. If control of bleeding was difficult by the pump, $0.5 \mathrm{mg}$ of adrenaline was added to $3000 \mathrm{~mL}$ of perfusate once or twice during the operation. When the operation time was extended and the action of the adrenaline was weakened, $250 \mathrm{~mm} \mathrm{Hg}$ air pressure was applied to the tourniquet attached to the proximal thigh.

A working space was created by shaving adipose and fibrous tissues just behind the os trigonum or posterior talar process, and the flexor hallucis longus (FHL) tendon was identified. The FHL tendon was a landmark to protect the neurovascular bundles in the tarsal tunnel. The os trigonum or posterior talar process was dissected free from the posterior talofibular ligament by bipolar electrocoagulation. The os trigonums were removed using meniscus rongeurs (Fig 1), and the posterior talar process was decompressed using a rounded burr to avoid interfering the FHL tendon (Fig 2). The arthroscope was introduced to the ankle joint after removing the os trigonum or the posterior talar process, along with the fibrous scars and proliferated synovium if they existed in the joint. Probing of the cartilage surface was also possible. In the ankle without bone impingement, inflamed, and/or synovial tissue, injured ligament fibers or fibrocartilage fragments occupied in the posterior ankle were removed (Fig 3).

In patients who complained of anterior ankle symptoms, anterior arthroscopy was performed 
Fig 1. Posterior arthroscopic view of the left ankle with a symptomatic os trigonum (OT) in a 23year-old female ballet dancer. (A) OT. (B) The OT was excised with forceps. (C) The posterior aspect of the ankle, subtalar joint, and the flexor hallucis ligament (FHL) tendon were visible.
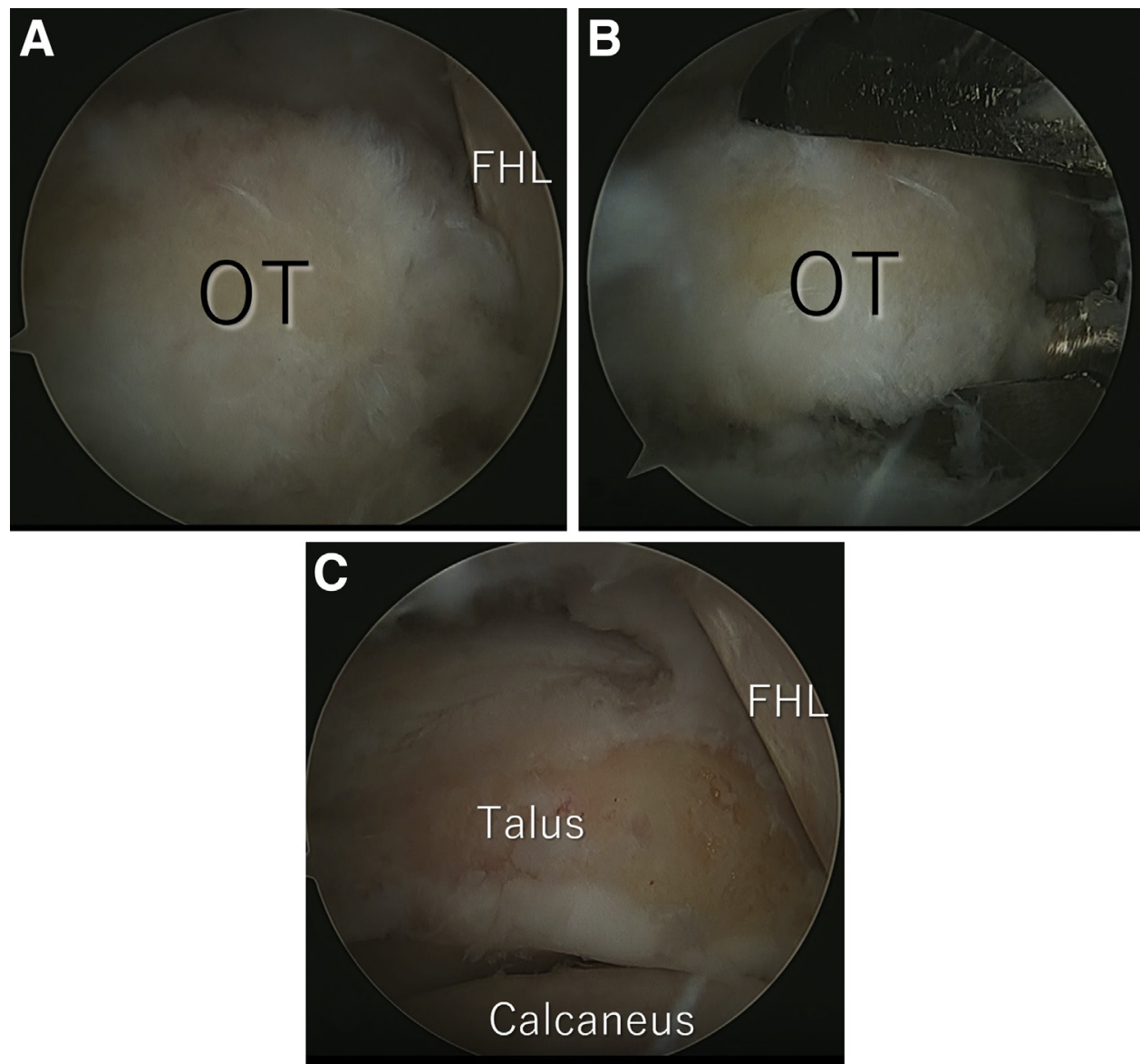

simultaneously, after a prone-to-supine position change. A traction device was used during anterior arthroscopy.

\section{Postoperative Treatment}

A compression bandage was applied for 24 hours after the operation and the patients were allowed early range of motion immediately following surgery. The patients were encouraged to walk without crutches from the next day, and they allowed to returned to work or school when as could tolerate their activities. Athletes were allowed to jog 2 weeks after the operation and increase their exercise intensity if they had no unbearable pain. Postoperative protocol of the lateral
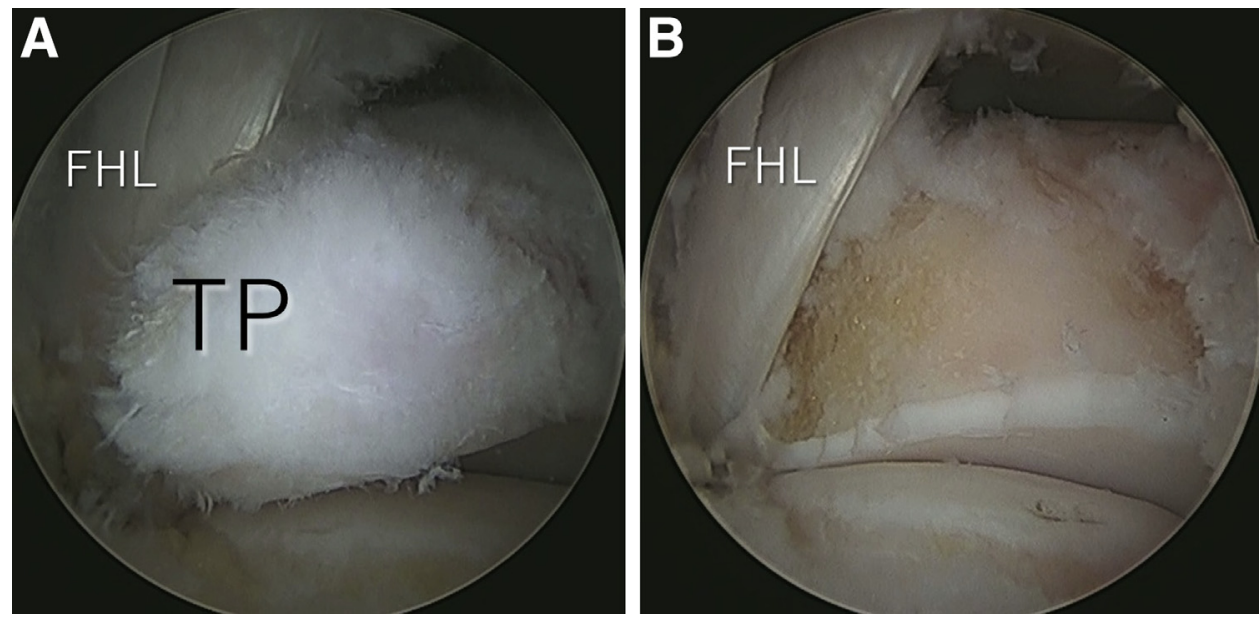

Fig 2. Posterior arthroscopic view of the right ankle with a symptomatic posterior talar process in a 21-year-old female gymnast. (A) A large talar process (TP). (B) The process was decompressed. (FHL, flexor hallucis ligament.) 

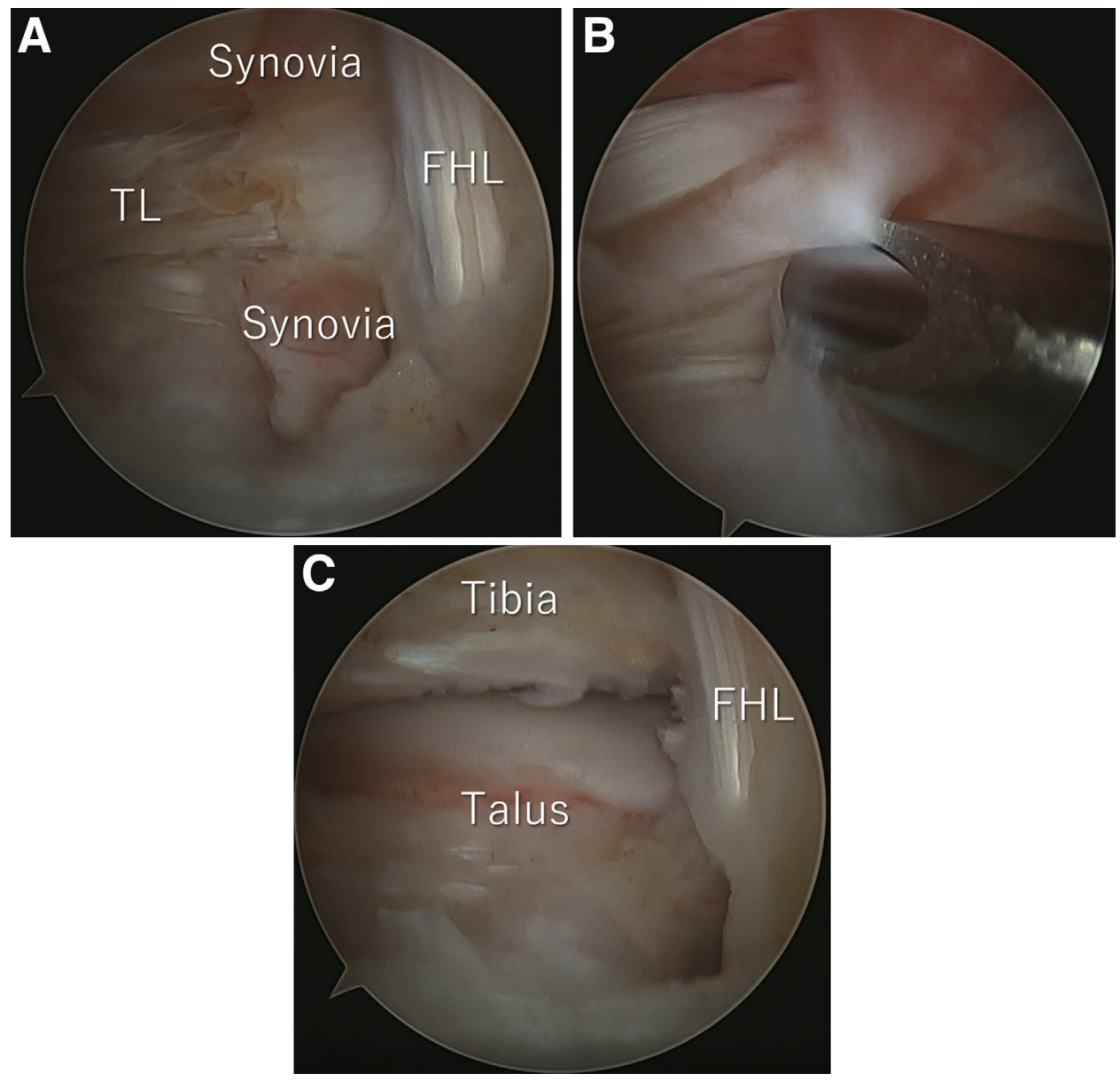

Fig 3. Posterior arthroscopic view of the left ankle with a soft-tissue impingement in a 22-year-old male rugby football player. (A) Inflamed synovia and thickened transverse ligament (TL). (B) These soft tissues were removed with a shaving instrument. (C) The posterior aspect of the ankle joint was visible. (FHL, flexor hallucis ligament.)

ankle ligament repair including a below-the-knee cast immobilization was applied in 4 patients who simultaneously underwent a repair of the anterior talofibular ligament.

\section{Clinical Evaluation and Follow-up}

The mean follow-up period was 60 months, ranging from 24 to 133 months. The AOFAS ankle and hindfoot clinical rating scale was used to evaluate preoperative and postoperative ankle conditions. Follow-up examination and interview were done by the 2 operators. All patients associated with sports were asked about their postoperative sports activity level along with the time required to resume training and to return to participating in a competition or getting on stage. Comparison of the AOFAS scores and recovery times was performed for the following: groups classified by causes; groups classified according to the patients' activity levels; groups according to the need of simultaneous anterior arthroscopy; and groups of the first and last 10 patients of the series who underwent surgery. Patients who underwent additional surgery before full recovery in sports for reasons other than the PAIS or who suspended sports activities due to work or entrance examinations were excluded from the assessment of recovery times.

\section{Learning Curve Assessment}

The surgical time was defined by making a skin incision to close the portals for a procedure as described by van Dijk et al., in all patients. The additional time of associated procedures for anterior impingements, ligament disorders, osteochondral lesions, or any lesions other than the PAIS was not included. The operation times in patients with a large posterior talar process or a soft-tissue problem were compared with those with os trigonum.

The learning effect of the endoscopic treatment of the PAIS was evaluated by changes in the operation time in the series. To eliminate the effects of variations in required treatments, the operation times required to treat ankles with the PAIS by (an) os trigonum(s) were used for a learning curve study. Altogether 50 operations were included in the learning curve study. The curve was determined using a logarithmic and a moving average trendline. Moving averages were calculated serially for every 10 operations. Every moving average was compared with the latest moving average and the 
Table 1. Demographics of Patients with the PAIS

\begin{tabular}{|c|c|c|c|c|}
\hline & \multicolumn{2}{|c|}{ Bony Impingement } & \multirow[b]{2}{*}{ Soft-Tissue Impingement } & \multirow[b]{2}{*}{ Overall } \\
\hline & Os Trigonum & Posterior Talar Process & & \\
\hline Ankles included in study ${ }^{*}$ & $50(69.4 \%)$ & $14(19.4 \%)$ & $8(11.1 \%)$ & $72(100.0 \%)$ \\
\hline Male sex ${ }^{*}$ & $22(44.0 \%)$ & $8(57.1 \%)$ & $5(62.5 \%)$ & $35(48.6 \%)$ \\
\hline \multicolumn{5}{|l|}{ Associated procedures } \\
\hline Anterior ankle arthroscopy ${ }^{*}$ & $10(20.0 \%)$ & $5(42.9 \%)$ & $1(12.5 \%)$ & $16(22.2 \%)$ \\
\hline Spur resection ${ }^{*}$ & $6(12.0 \%)^{\ddagger}$ & $5(28.6 \%)$ & $0(0.0 \%)$ & $11(15.3 \%)$ \\
\hline Additional surgeries ${ }^{*}$ & $2(4.0 \%)$ & $1(7.1 \%)$ & $3(37.5 \%)$ & $6(8.3 \%)$ \\
\hline Follow-up periods, mo ${ }^{\dagger}$ & $60.3 \pm 37.2(24-133)$ & $70.2 \pm 43.2(24-123)$ & $39.6 \pm 14.3(24-62)$ & $60.0 \pm 37.2(24-133)$ \\
\hline \multirow{2}{*}{\multicolumn{5}{|c|}{ BMS, bone marrow stimulation; OLT, osteochondral lesion of the talus; PAIS, posterior ankle impingement syndrome. }} \\
\hline & & & & \\
\hline \multicolumn{5}{|c|}{${ }^{\dagger}$ Values are given as the mean and standard deviation with range in parenthesis. } \\
\hline
\end{tabular}

average AOFAS score in the initial and the latest 10 series were compared.

\section{Statistical Analysis}

Statistical analysis was performed using Microsoft Excel with Statcel 4 software (OMS Publishing Inc., Saitama, Japan). Normality of variance was measured using the Shapiro-Wilk test, and equality of variance by F-test and Bartlett's test. Surgical times were assessed using analysis of variance followed by the Bonferroni-Dann post-hoc method. The AOFAS scores were assessed using the Kruskal-Wallis test and the Wilcoxon signed-rank test. The required time to return to sports activities was measured using the Kruskal-Wallis test and Steel-Dwass test. Categorical data were calculated using the $\chi^{2}$ test. A threshold of $P<.05$ was considered statistically significant.

\section{Results}

\section{Study Population}

There were 67 patients with 80 ankles were treated by posterior arthroscopy. After exclusion of patients with a loose body (3), a bipartite talus (1), and those followed less 24 months (4), 72 ankles of 59 patients were evaluated. There were 29 male patients (35 ankles) and 30 female patients ( 37 ankles), with a mean age of $21.8 \pm 9.6$ years (range, 12-74) at the time of surgery. Of the 72 ankles, 64 were bony impingements: os trigonum (50), a large talar process ${ }^{14}$, and 8 were soft-tissue impingements (Table 1). In 17 of 72 ankles, pain also was induced by contraction of the FHL muscle. The initial 7 patients were operated under spinal anesthesia at the Imperial Gift Saiseikai Nara Hospital and those later under general anesthesia at the Nara Prefecture General Medical Center. Fifty-six of 59 patients and were sports-related, which included 24 patients with 30 ankles were classified in S1, 19 patients (24 ankles) in S2, and 13 patients ( 15 ankles) in S3.

\section{Patients Demographics}

There were no differences in the patients' age and male-female ratio in each group. Arthroscopic treatment from the anterior portals was simultaneously performed in 16 of 72 ankles $(22.2 \%)$, and repair of the anterior talofibular ligament in 4 ankles $(5.6 \%)$ (Table 1). There were 2 patients who underwent bone marrow stimulation for an osteochondral lesion of the talus, and one of them had an osteochondral autograft implantation after 6 months.

Of the 56 patients with sports-related symptoms, 4 patients underwent additional surgeries for diseases other than the PAIS within 6 months, and 4 others interrupted the sports activities due to social factors. These 8 patients with 11 ankles were excluded from the evaluation of the required time to resume sports activity (Table 2).

\section{Clinical Results}

The preoperative average AOFAS scores improved from $79.6 \pm 6.3$ to $97.6 \pm 4.7$ postoperatively. There was significant improvement $(P<.001)$ of the AOFAS scores from the preoperative to latest follow-up for all the groups (Table 2). Differences between the groups classified by causes were not detected pre- and postoperatively.

All patients associated with sports returned to their original activities. Differences in the scores between the groups classified by sports performance levels were not detected pre- and postoperatively (Table 3). The average time required to resume training was $5.3 \pm 3.4$ weeks, and the time required to return to a state of 
Table 2. Surgical Times and Clinical Outcomes With Sports Activities According to Causes of the PAIS

\begin{tabular}{|c|c|c|c|c|}
\hline & \multicolumn{2}{|c|}{ Bony Impingement } & \multirow[b]{2}{*}{$\begin{array}{l}\text { Soft-Tissue } \\
\text { Impingement }\end{array}$} & \multirow[b]{2}{*}{$P$ Value } \\
\hline & Os Trigonum & $\begin{array}{c}\text { Posterior Talar } \\
\text { Process } \\
\end{array}$ & & \\
\hline Ankles included in study, $\mathrm{n}$ & 50 & 14 & 8 & \\
\hline \multicolumn{5}{|l|}{ AOFAS ankle/hindfoot score } \\
\hline Preoperative & $79.2 \pm 6.6(66-87)$ & $80.9 \pm 5.6(74-87)$ & $80.1 \pm 5.9(72-87)$ & n.s. \\
\hline Postoperative ${ }^{*}$ & $98.1 \pm 4.1(87-100)$ & $95.1 \pm 6.0(87-100)$ & $98.4 \pm 4.6(87-100)$ & n.s. \\
\hline \multicolumn{5}{|c|}{ Required time to return to sports } \\
\hline No. of ankles, $\mathrm{n}$ & 41 & 9 & 8 & \\
\hline Original training, $\mathrm{wk}^{*}$ & $5.0 \pm 3.0(2-14)$ & $4.7 \pm 3.1(2-12)$ & $6.3 \pm 4.3(3-13)$ & n.s. \\
\hline Full recovery in sports, $\mathrm{wk}^{*}$ & $13.6 \pm 7.5(4-36)$ & $11.6 \pm 6.3(4-25)$ & $14.3 \pm 7.2(7-26)$ & n.s. \\
\hline
\end{tabular}

participating in a competition or getting on stage was $13.4 \pm 7.2$ weeks. The required time to resume training was shorter in the level 1 group than in the level 2 group. There was no statistical difference of the time required to return to a competitive athletic level between the groups classified by sports performance level. The average postoperative AOFAS scores in patients with and without simultaneous anterior ankle arthroscopy were $75.9 \pm 5.8$ and $98.9 \pm 4.2$. The required time to resume training in patients with and without simultaneous anterior ankle arthroscopy were $6.3 \pm 4.2$ weeks and $4.8 \pm 2.9$ weeks, and the required times for full recovery were $15.9 \pm 8.1$ weeks and 12.8 \pm 6.9 weeks in mean. There were no statistical differences in the clinical results and required time to resume sports activity between the group with and without simultaneous anterior arthroscopy. There were no statistical differences in the clinical results or recovery time for sports ability between the early and latest series of the PAIS due to os trigonum (Table 4).

\section{Complications}

In the early series, superficial skin flashes of the anterior ankle occurred in 3 patients operated using monopolar electrocoagulation with an indifferent electrode. However, there were no skin flashes after the electrocoagulation system was changed to bipolar. A male college swimmer complained of a recurrent

Table 3. Clinical Outcomes According to Sport Activity Levels

\begin{tabular}{|c|c|c|c|c|}
\hline & Level 1 & Level 2 & Level 3 & $P$ Value \\
\hline No. of ankles (patients) & $30(24)$ & $24(19)$ & $15(13)$ & \\
\hline \multicolumn{5}{|l|}{ Causes of PAIS (ankles) } \\
\hline Os trigonum & 19 & 16 & 15 & \\
\hline Soft tissue impingement & 4 & 3 & 0 & \\
\hline \multicolumn{5}{|l|}{ AOFAS ankle/hindfoot score } \\
\hline Preoperative & $81.2 \pm 6.0(67-87)$ & $78.0 \pm 5.8(66-87)$ & $79.3 \pm 7.3(67-87)$ & n.s. \\
\hline Return to sports activity ${ }^{*}$ & $25 / 25(100.0)$ & $20 / 20(100.0)$ & $13 / 13(100.0)$ & n.s. \\
\hline \multicolumn{5}{|c|}{ Required time to return to sports } \\
\hline No. of ankles, n & 25 & 20 & 13 & \\
\hline Original training, $\mathrm{wk}^{*}$ & $3.9 \pm 2.1(2-12)$ & $6.2 \pm 3.2(2-13)$ & $5.8 \pm 4.1(2-14)$ & $.031^{\S}$ \\
\hline Full recovery, wk ${ }^{*}$ & $11.5 \pm 5.4(4-25)$ & $13.7 \pm 7.6(5-26)$ & $16.5 \pm 8.9(8-36)$ & n.s. \\
\hline
\end{tabular}

AOFAS, The American Orthopaedic Foot and Ankle Society; n.s., not significant; PAIS, posterior ankle impingement syndrome.

*Values are given as mean and standard deviation with range in parenthesis.

${ }^{\dagger}$ Comparison of pre- and postoperative scores.

${ }^{\ddagger}$ Ankles with patients who underwent additional surgery before full recovery in sports for reasons other than the PAIS, or who suspended sports activities due to work or entrance exams are excluded.

${ }^{\S}$ Difference is statistically significant between level 1 and 2 groups. 
Table 4. Clinical Outcomes of the Early and the Latest 10 Series of the PAIS due to Os Trigonum

\begin{tabular}{|c|c|c|c|}
\hline & Early 10 Series ${ }^{*}$ & Latest 10 Series* & $P$ Value \\
\hline No. of ankles & 10 & 10 & \\
\hline AOFAS ankle/hindfoot score & $80.6 \pm 5.6(75-87)$ & $81.5 \pm 6.0(72-87)$ & \\
\hline Preoperative $^{\dagger}$ & $81.8 \pm 5.6(77-87)$ & $81.1 \pm 6.3(74-87)$ & n.s. \\
\hline \multicolumn{4}{|l|}{ Required time to return to sports } \\
\hline Original training, $\mathrm{wk}^{\dagger}$ & $4.4 \pm 1.4(2-6)$ & $5.6 \pm 1.6(3-8)$ & n.s. \\
\hline Full recovery in sports, $w^{\dagger}$ & $16.7 \pm 9.8(7-36)$ & $13.6 \pm 6.6(6-25)$ & n.s. \\
\hline
\end{tabular}

AOFAS, The American Orthopaedic Foot and Ankle Society; n.s., not significant; PAIS, posterior ankle impingement syndrome.

*Patients underwent simultaneous anterior arthroscopy and related surgery, or who underwent an additional surgery for reasons other than the PAIS, or who suspended sports activities due to work or entrance examinations are excluded.

${ }^{\dagger}$ Values are given as mean and standard deviation with range in parenthesis.

symptom 1 year after the operation. A scar formation of the connective tissue just behind the ankle was suspected on MRI, and the second operation was performed to remove the scar. The patient complained of no symptoms 3 years after the second operation. These complications occurred in the early series, and there were no complications in the latter half of the series.

\section{Surgical Time and Learning Curve}

The average surgical time for the van Dijk procedure was statistically different between the groups. The surgical time for soft-tissue impingement was $23.9 \mathrm{mi}-$ nutes longer than that for excision of os trigonum (Table 2).

The operation times in the patients with os trigonum are plotted by the order of operation and the best-fit learning curve is shown by a logarithmic trendline (Fig 4). The mathematical formula was $y=-14.37 \mathrm{ln}$ (x) -105.35 (y: operation time to be estimated, $x$ : order number of the series).

The moving average of the operation time is shown in Figure 5. The moving average of the operation time was calculated in every 10 operations serially, and each average time was compared with the average operation time of the latest 10 ankles. The $P$ values of each comparison are shown in Figure 6. The $P$ values were less than .05 from the initial to the 16th moving average, and were over .05 after the 17th moving average.

\section{Discussion}

In our series, the AOFAS scores improved in all groups, with all the athletes and dancers resuming their original activities. A learning curve was detected in the arthroscopic treatment of the PAIS. Nevertheless, the mid-term clinical results of arthroscopic treatment were good regardless of the order of the case in the series and the cause of impingement.

Posterior ankle bony impingements by the os trigonum or large posterior talar process detected by radiographs had been commonly treated by open surgery. $^{29-31}$ Arthroscopic examination brought new knowledge to the physicians on the posterior ankle lesions, including soft-tissue impingements, ${ }^{32}$ and several authors published good short-term results of the arthroscopic treatment for the PAIS with follow-up periods of 12 to 30 months. $^{1-3,6,16,17,19,20,26}$ López Valerio et al. ${ }^{4}$ reported mid-term results of arthroscopic treatment for the PAIS with a mean follow-up period of 6.5 years, whereas Georgiannos et al. ${ }^{5}$ reported those with a mean follow-up period of 5 years. The cause of the PAIS in these 2 reports was os trigonum, and patients with a large talar process or soft-tissue impingement were not included. ${ }^{4,5}$

The endoscopic or arthroscopic approach to the posterior ankle requires removing soft tissues including the posterior capsule of the ankle and hindfoot for a working space with good visualization. The FHL tendon sheath also was removed to examine the medial border of the os trigonum or the posterior talar process. We deduced from the good mid-term results in our series and the reports by López Valerio et al. and Georgiannos et al., ${ }^{4,5}$ that resection of the capsule and tendon sheath did not seemed to affect the results.

The required duration to return to sports activity, varying in literature ( 34 days to 11.5 weeks), confuses patients. In this study, the time to resume ordinal training and time to be competitive or get on stage were

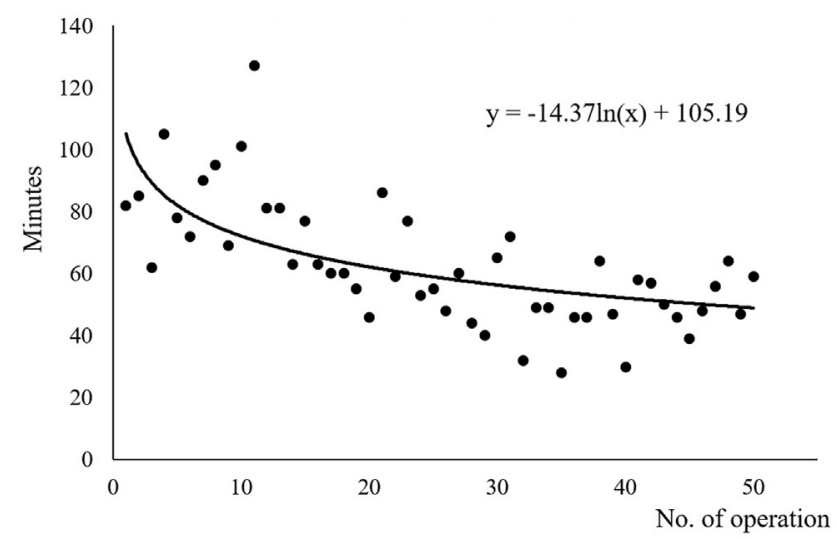

Fig 4. The learning curve figured by a logarithmic trendline. 


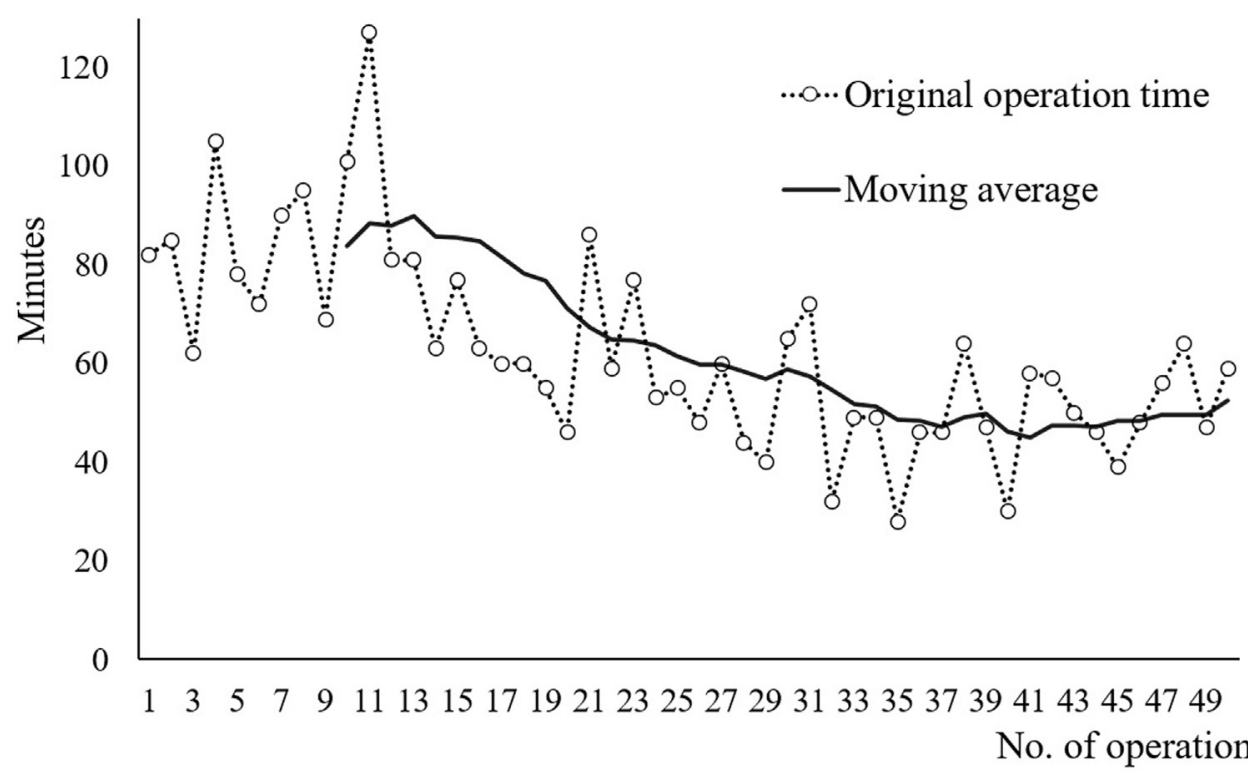

Fig 5. The learning curve figured by moving averages.

separately assessed. The critical issue of the treatment in athletes and dancers is the number of days required to returned to the maximal physical condition. The obtained data of the average time to resume original training was 5.1 weeks, and the average time to return to a state of competitive sports performance was 13.4 weeks.

Georgiannos et al. ${ }^{5}$ reported that the mean time taken to start training was 4.58 weeks and the mean time to return to previous sports level was 7.12 weeks after arthroscopic treatment of the PAIS. The average time to resumption of training in our patient series was similar to that reported by Georgiannos et al. We defined the complete resumption to sports as participation in athletic competitions. The required time to a complete return to sports was not comparable with the time to returned previous activity levels.

In our series, the required times to resume original training were shorter in the level $l$ athletes than in the level 2 athletes. Top athletes had personal or team trainers, which may have accelerated their return to their original training. However, there was no statistical difference in the time required to return to a state of participation in a competition between the activity levels.

To perform a safe and sophisticated operation, surgeons must be familiar with the anatomy of the posterior part of the ankle and hindfoot, as blind shaving to

Fig 6. $P$ values of each moving average of the surgical time compared with average time of

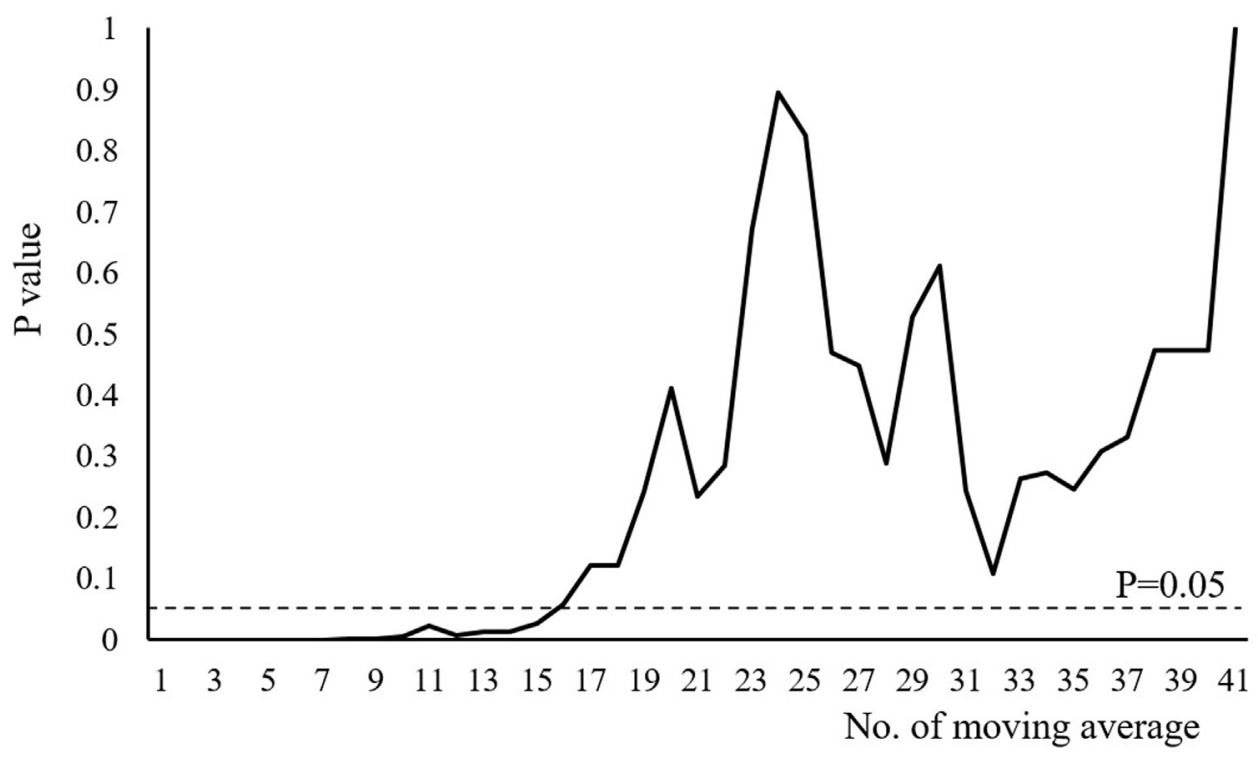
the latest 10 operations. 
obtain a working space without sufficient anatomical knowledge and experience has the risks of injuring tendons, major vessels, and nerves. ${ }^{9,33-35}$

The learning curve of the technique has been reported previously. Yamakado ${ }^{25}$ reported a learning curve of 23 serial operations with a symptomatic os trigonum. The report suggested that 16 patients were required to ensure a relatively comfortable experience level of experience.

In our series, the endoscopic treatments of the PAIS were performed by 2 senior operators (K.S. and S.I.). The average operation time to remove causes of the impingement was longer in patients with soft-tissue problems compared with that with (an) os trigonum(s). Excision of the os trigonum is performed through a uniform endoscopic procedure for the PAIS. However, in our experience endoscopic procedures for a large talar process and soft tissue problems vary from patient to patient.

The "learning effect" was noted by Wright ${ }^{36}$ in connection with aircraft production and evaluation of the learning curve was developed in psychology and economics. $^{37,38}$ A logarithmic trendline is a best-fit curved line, most useful when there are quick increases or decreases in the rate of change in the data followed by leveling out. ${ }^{39}$ Many studies use the logarithmic trendline to show the learning curve in surgery. ${ }^{25}$

The asymptote of a specific operation is determined not only by the operating time but also by various factors such as intraoperative blood loss, operation effectiveness, length of hospital stay, and complications, as well as the surgeon's preference for the procedure. However, time-based metrics were the most commonly reported variables used to assess the learning curve. ${ }^{29} \mathrm{~A}$ trendline of our experience in endoscopic excision of os trigonum was drawn smoothly and made it easier to understand our development. A moving average is commonly used with time series data to smooth out short-time fluctuations. Every moving average shows the actual average of the specific term. The average time of each specific number of operations is comparable to the latest average.

From the logarithmic trendline, the operation time for os trigonum in our series was found to be below 60 minutes after the 24 th operation. The moving averages from the initial 10th to 17th operations differed statistically compared with the latest 10 operations. This suggested that the basic skill of the hindfoot endoscopy was established after 26 operations. The expected surgery time after 10, 100, and 200 clinical practices calculated by the mathematical formula of the logarithmic trendline were 72, 39, and $29 \mathrm{~min}$, respectively.

Fortunately, longer operative times in our early series compared with those in the latest series did not affect the clinical scores at the final follow-up, and the recovery speed in athletic activities. Complications occurring early in the series were not serious and did not affect the final outcome.

\section{Limitations}

In this study, assessment of the patients who met minimal clinically important difference, substantial clinical benefit, or patient acceptable symptomatic state for patient-reported outcome measures (PROMs) ${ }^{40}$ was not performed. The Self-Administered Foot Evaluation Questionnaire $^{41}$ has been used for PROMs since 2013. Preoperative assessment scores by the SelfAdministered Foot Evaluation Questionnaire were not obtained in 34 patients in the series who had been operated before 2013; assessment for PROMs was not included in this study. The studies are the small number of ankles with a large posterior talar process and softtissue problems. Further long-term follow-up studies on the PAIS without os trigonum in relation with soft tissues are needed.

We used the operation time as a means of determining the learning curve. Only the ankles with the PAIS due to os trigonum were targeted to ensure consistency. However, shortened surgery time may not be representative of technical success, clinical outcome, or complications, or the operative skill of the surgeon.

\section{Conclusions}

The mid-term follow-up results of endoscopic treatment for the PAIS were good, with a high success rate in returning to sports activities. Although a learning curve effect was detected in our series of arthroscopic treatment for the PAIS due to os trigonum, a low volume of experience did not affect the results.

\section{References}

1. Ballal MS, Roche A, Brodrick A, Williams RL, Calder JD. Posterior endoscopic excision of os trigonum in professional national ballet dancers. J Foot Ankle Surg 2016;55:927-930.

2. Coetzee JC, Seybold JD, Moser BR, Stone RM. Management of posterior impingement in the ankle in athletes and dancers. Foot Ankle Int 2015;36:988-994.

3. Kudaş S, Dönmez G, Işık Ç, Çelebi M, Çay N, Bozkurt M. Posterior ankle impingement syndrome in football players: Case series of 26 elite athletes. Acta Orthop Traumatol Turc 2016;50:649-654.

4. López Valerio V, Seijas R, Alvarez P, et al. Endoscopic repair of posterior ankle impingement syndrome due to os trigonum in soccer players. Foot Ankle Int 2015;36:70-74.

5. Georgiannos D, Bisbinas I. Endoscopic versus open excision of os trigonum for the treatment of posterior ankle impingement syndrome in an athletic population: A randomized controlled study with 5-year follow-up. Am J Sports Med 2017;45:1388-1394.

6. Morelli F, Mazza D, Serlorenzi P, et al. Endoscopic excision of symptomatic os trigonum in professional dancers. J Foot Ankle Surg 2017;56:22-25. 
7. Ribbans WJ, Ribbans HA, Cruickshank JA, Wood EV. The management of posterior ankle impingement syndrome in sport: A review. Foot Ankle Surg 2015;21:1-10.

8. Vilá J, Vega J, Mellado M, Ramazzini R, Golanó P. Hindfoot endoscopy for the treatment of posterior ankle impingement syndrome: A safe and reproducible technique. Foot Ankle Surg 2014;20:174-179.

9. Ferkel RD. Subtalar arthroscopy. In: Ferkel RD, ed. Arthroscopic surgery: The foot and ankle. Philadelphia: Lippincott, 1996.

10. Jerosch J. Subtalar arthroscopy: Indications and surgical technique. Knee Surg Sports Traumatol Arthrosc 1998;6: 122-128.

11. Marumoto JM, Ferkel RD. Arthroscopic excision of the os trigonum: A new technique with preliminary clinical results. Foot Ankle Int 1997;18:777-784.

12. Williams MM, Ferkel RD. Subtalar arthroscopy: Indications, technique, and results. Arthroscopy 1998;14: 373-381.

13. van Dijk CN, Scholten PE, Krips R. A 2-portal endoscopic approach for diagnosis and treatment of posterior ankle pathology. Arthroscopy 2000;16:871-876.

14. Scholten PE, Sierevelt IN, van Dijk CN. Hindfoot endoscopy for posterior ankle impingement. J Bone Joint Surg Am 2008;90:2665-2672.

15. van Dijk CN, de Leeuw PAJ, Scholten PE. Hindfoot endoscopy for posterior ankle impingement, surgical technique. J Bone Joint Surg Am 2009;91:287-298 (suppl 2).

16. Miyamoto W, Miki S, Kawano H, Takao M. Surgical outcome of posterior ankle impingement syndrome with concomitant ankle disorders treated simultaneously in patient engaged in athletic activity. J Orthop Sci 2017;22: 463-467.

17. Noguchi H, Ishii Y, Takeda M, Hasegawa A, Monden S, Takagishi K. Arthroscopic excision of posterior ankle bony impingement for early return to the field: Short-term results. Foot Ankle Int 2010;31:398-403.

18. Pearce CJ, Calder JDF. Posterior ankle arthroscopy in sports: Posterior impingement/os trigonum. Oper Tech Orthop 2008;18:271-276.

19. Smyth NA, Murawski CD, Levine DS. Hindfoot arthroscopic surgery for posterior ankle impingement: A systematic surgical approach and case series. Am J Sports Med 2013;41:1869-1876.

20. Willits K, Sonneveld H, Amendola A, Giffin JR, Griffin S, Fowler PJ. Outcome of posterior ankle arthroscopy for hindfoot impingement. Arthroscopy 2008;24:196-202.

21. Zwiers R, Wiegerinck JI, Murawski CD, Smyth NA, Kennedy JG, van Dijk CN. Surgical treatment for posterior ankle impingement. Arthroscopy 2013;29:1263-1270.

22. Heier KA, Hanson TW. Posterior ankle impingement Syndrome. Oper Tech Sports Med 2017;25:75-81.

23. Nickisch F, Barg A, Saltzman CL, et al. Postoperative complications of posterior ankle and hindfoot arthroscopy. J Bone Joint Surg Am 2012;94:439-446.
24. Tryfondidis M, Whitfield CG, Charalambous CP, Baraza WK, Zubairy AI, Blundel CM. Posterior ankle arthroscopy portal safety regarding proximity to the tibial and sural nerves. Acta Orthop Belg 2008;74:370-373.

25. Yamakado K. Quantification of the learning curve for arthroscopic os trigonum excision. J Foot Ankle Surg 2018;57:505-508.

26. Yilmaz C, Eskandari MM. Arthroscopic excision of the talar Stieda's process. Arthroscopy 2006;22:225.

27. Abramowitz Y, Wollstein R, Barzilay Y, et al. Outcome of resection of a symptomatic os trigonum. J Bone Joint Surg Am 2003;85:1051-1057.

28. Nomura K, Yoshida M. assessment of the learning curve for microendoscopic decompression surgery for lumbar spinal canal stenosis through an analysis of 480 cases involving a single surgeon. Global Spine J 2017;7:54-58.

29. Soomro NA, Hashimoto DA, Porteous AJ, et al. Systematic review of learning curves in robot-assisted surgery. BJS Open 2020;4:27-44.

30. Hamilton WG, Geppert MJ, Thompson FM. Pain in the posterior aspect of the ankle in dancers: Differential diagnosis and operative treatment. J Bone Joint Surg Am 1996;78:1491-1500.

31. Marotta JJ, Micheli LJ. Os trigonum impingement in dancers. Am J Sports Med 1992;20:533-536.

32. Hayashi D, Roemer FW, D'Hooghe P, Guermazi A. Posterior ankle impingement in athletes: Pathogenesis, imaging features and differential diagnoses. Eur J Radiol 2015;84:2231-2241.

33. Lijoi F, Lughi M, Baccarani G. Posterior arthroscopic approach to the ankle: An anatomic study. Arthroscopy 2003;19:62-67.

34. Stiler DF, Amendola A, Bailey CS, Thain LMF, Spouge A. Posterior ankle arthroscopy: An anatomical study. J Bone Joint Surg Am 2002:84763-84769.

35. Voto SJ, Ewing JW, Fleissner PR Jr, Alfonso M, Kufel M. Ankle arthroscopy: Neurovascular and arthroscopic anatomy of standard and trans-Achilles tendon portal placement. Arthroscopy 1989;5:41-46.

36. Wright TP. Factors affecting the cost of airplanes. J Aeronautical Sci 1936;3:122-128.

37. Bills AG. General experimental psychology. Longmans Psychology Series. New York, NY: Longmans, Green and Co, 1934.

38. Shakow D. Hermann Ebbinghaus. Am J Psychol 1930;42: 505-518.

39. Newell A, Rosenbloom PS. Mechanisms of skill acquisition and the law of practice. In: Anderson JR, ed. Cognitive skills and their acquisition. Hillsdale, NJ: Erlbaum, 1981.

40. Harris JD, Brand JC, Cote MP, et al. Research pearls: The significance of statistics and perils of pooling. Part 1: Clinical versus statistical significance. Arthroscopy 2017;33: 1102-1112.

41. Niki H, Tatsunami S, Haraguchi N, et al. Validity and reliability of a self-administered foot evaluation questionnaire (SAFE-Q). Orthop Sci 2013;18:298-320. 